\title{
The impact of transcatheter aortic valve implantation on left ventricular performance and wall thickness - single-centre experience
}

\author{
Patrycjusz Stokłosa ${ }^{1}$, Piotr Szymański ${ }^{1}$, Maciej Dąbrowski ${ }^{2}$, Dariusz Zakrzewski ${ }^{1}$, Piotr Michałek ${ }^{3}$, \\ Ewa Orłowska-Baranowska ${ }^{1}$, Kamal El-Hassan ${ }^{4}$, Zbigniew Chmielak², Adam Witkowski², Tomasz Hryniewiecki ${ }^{1}$ \\ ${ }^{1}$ Department of Valvular Heart Disease, Institute of Cardiology, Warsaw, Poland \\ ${ }^{2}$ Department of Interventional Cardiology and Angiology, Institute of Cardiology, Warsaw, Poland \\ ${ }^{3}$ Emergency Ward, Institute of Cardiology, Warsaw, Poland \\ ${ }^{4}$ Medical University of Warsaw, Poland
}

Postep Kardiol Inter 2015; 11, 1 (39): 37-43

DOI: $10.5114 /$ pwki.2015.49183

\begin{abstract}
A bstract
Introduction: Transcatheter aortic valve implantation (TAVI) is a treatment alternative for the elderly population with severe symptomatic aortic stenosis (AS) at high risk for surgical aortic valve replacement (SAVR).

Aim: To assess the impact of TAVI on echocardiographic parameters of left ventricular (LV) performance and wall thickness in patients subjected to the procedure in a single-centre between 2009 and 2013.

Material and methods: The initial group consisted of 170 consecutive patients with severe AS unsuitable for SAVR. Logistic European System for Cardiac Operative Risk Evaluation (EuroSCORE) was $21.73 \pm 12.42 \%$ and mean age was $79.9 \pm 7.5$ years.

Results: The TAVI was performed in $167(98.2 \%)$ patients. Mean aortic gradient decreased significantly more rapidly after the procedure (from $58.6 \pm 16.7 \mathrm{~mm} \mathrm{Hg}$ to $11.9 \pm 4.9 \mathrm{~mm} \mathrm{Hg}, p<0.001$ ). The LV ejection fraction (LVEF) significantly increased in both short-term and long-term follow-up ( $57 \pm 14 \%$ vs. $59 \pm 13 \%, p<0.001$ and $56 \pm 14 \%$ vs. $60 \pm 12 \%, p<0.001$, respectively). Significant regression of interventricular septum diameter at end-diastole (IVSDD) and end-diastolic posterior wall thickness (EDPWth) was noted in early ( $15.0 \pm 2.4 \mathrm{~mm}$ vs. $14.5 \pm 2.3 \mathrm{~mm}, p<0.001$ and $12.7 \pm 2.1 \mathrm{~mm}$ vs. $12.4 \pm 1.9 \mathrm{~mm}, p<0.028$, respectively) and late post-TAVI period (15.1 $\pm 2.5 \mathrm{~mm}$ to $14.3 \pm 2.5 \mathrm{~mm}, p<0.001$ and $12.8 \pm 2.0 \mathrm{~mm}$ to $12.4 \pm 1.9 \mathrm{~mm}, p<0.007$, respectively). Significant paravalvular leak (PL) was noted in $21(13.1 \%)$ patients immediately after TAVI and in $13(9.6 \%)$ patients in follow-up $(p<0.001)$. Moderate or severe mitral regurgitation (msMR) was seen in $24(14.9 \%)$ patients from the initial group and in $19(11.8 \%)$ patients after TAVI $(p<0.001)$.

Conclusions: The TAVI had an immediate beneficial effect on LVEF, LV walls thickness, and the incidence of msMR. The results of the procedure are comparable with those described in other centres.
\end{abstract}

Key words: aortic stenosis, transcatheter aortic valve implantation, echocardiography.

\section{Introduction}

Degenerative aortic stenosis (AS) is the most common valvular heart disease in the ageing population of Northern America and Europe. According to current registers, AS occurs in $12.4 \%$ of people aged 75 years and over, including $3.4 \%$ of people with haemodynamically significant pathology [1]. In case of severe symptomatic AS or asymptomatic but with concomitant left ventricular (LV) systolic dysfunction, the treatment of choice is surgical aortic valve replacement (SAVR) [2-4]. However, a significant number of patients with severe AS - estimated at up to $30 \%$ - cannot be treated traditionally due to high surgical risk (HSR) and/or contraindications to SAVR by standard median sternotomy $[5,6]$. Successfully performed for the first time in France in 2002 by Cribier et al., the transcatheter aortic valve implantation (TAVI) procedure has proved to be a safe alternative to SAVR in this group of patients [7]. Moreover, according to the results of CoreValve High-Risk Study, in patients with severe AS and HSR, 1-year all-cause mortality is significantly lower in TAVI than in the SAVR group [8].

Until now, a number of studies concerning the effects of TAVI on echocardiographic parameters in HSR patients have been published worldwide. It was proven that the

Corresponding author:

Patrycjusz Stokłosa MD, Department of Valvular Heart Disease, Institute of Cardiology, 42 Alpejska St, 04-628 Warsaw, Poland,

phone: +48 502474 913, e-mail: patryk.stoklosa@wp.pl

Received: 23.01.2015, accepted: 26.01.2015. 
procedure effectively reduces maximal and mean aortic gradients [9] as well as improves LV ejection fraction (LVEF) [10-12] and is associated with the occurrence of paravalvular leak $(\mathrm{PL})[13,14]$ and the reduction of severity of mitral regurgitation (MR) [15]. The impact of TAVI on regression of LV hypertrophy (LVH) [16-20] was presented in few studies, and according to the latest analysis of the Placement of Aortic Transcatheter Valves (PARTNER) trial, LVH regression significantly reduced re-hospitalisations, specifically for heart failure [20].

Our study reports single-centre experiences in TAVI procedures and echocardiographic evaluation of the population treated in the Cardinal Stefan Wyszynski Institute of Cardiology in Warsaw. There has been no such observation in Poland yet. Moreover, currently the largest group of patients in the country, who have been subjected to TAVI, are just in our centre.

\section{Aim}

The aim of this study is to report the influence of TAVI on echocardiographic parameters in a large population of patients with severe AS treated in one medical centre between 2009 and 2013.

\section{Material and methods}

It was a single-centre - up to 2013 , retrospective long-term follow-up analysis. Initially, all 171 patients who qualified for TAVI in our medical centre between January 2009 and September 2013 were included in the study. One female patient was excluded from the group due to the dysfunction of calcified aortic homograft with severe aortic regurgitation (AR) and HSR as a reason to perform TAVI. Finally, 170 patients with severe symptomatic AS were included.

The following patients were qualified the procedure: with severe symptomatic AS and aortic valve area (AVA) $<1 \mathrm{~cm}^{2}$, unsuitable for SAVR due to HSR and logistic EurOSCORE $[21,22] \geq 20 \%$ or logistic EuroSCORE $<20 \%$, but with debilitating comorbid condition or predictor of adverse outcomes as past mediastinal radiotherapy, coronary artery bypass grafting (CABG) with internal thoracic artery and risk of the graft injury during sternotomy or porcelain aorta, as well as frailty syndrome [23-26]. The qualification process was conducted by the local Heart Team, consisting of clinical and interventional cardiologists, a cardiovascular surgeon, a neurologist, and an anaesthesiologist. Informed consent for diagnostic and treatment procedures was obtained from all the patients. Every patient was subjected to a complete medical assessment - anamnesis, physical examination, and laboratory tests were done as well as an electrocardiogram, a chest X-ray, a transthoracic echocardiography (TTE), a transoesophageal echocardiography (TEE), a coronary assessment with angiography or computed tomography (CT), and vascular access assessment with CT imaging.

\section{Transcatheter aortic valve implantation technique}

Transcatheter aortic valve implantation was performed in a hybrid operating room. The procedures were conducted under general or local anaesthesia with sedation [27]. The valves were implanted via transfemoral, transapical, transaortic, trans-subclavian, or transaxillary approach. The following types of valves were used: CoreValve (CV) no. 26, 29, and 31 or Engager valve (EV) no. 26 (Medtronic), as well as Edwards-Sapien (ES) no. 23 and 26, and SapienXT (SXT) no. 23, 26, and 29 (Edwards Lifesciences). The type of valve and the implantation access route (anterograde or retrograde approach) was established on the basis of the results of TEE and CT imaging. The device success was defined as a proper prosthesis placement with aortic mean gradient less than $20 \mathrm{~mm} \mathrm{Hg}$, without significant (i.e. moderate/severe) AR [24]. The procedure success was defined as an effective valve implantation procedure with no death within $24 \mathrm{~h}$ and no need for conversion to surgery.

\section{Echocardiography and Doppler measurements}

A standard complete TTE was performed in each patient prior to the procedure and after TAVI before hospital discharge. Also, at least one complete TTE was performed during the follow-up period if the patient was still alive and was able to come for a medical check-up. Echocardiograms, including Doppler measurements, were done according to current recommendations [28-32].

Echocardiographic measurements and haemodynamic calculations were performed by qualified echocardiographers experienced in the quantitative assessment of valvular heart diseases. The examinations were performed by using the following devices: Vivid 6S, Vivid E7 and E9 (General Electric Medical Systems, Milwaukee, WI, USA), and iE33 and HD15 (Philips, Andover, Massachusetts, USA). Left ventricular end-diastolic diameter (LVEDD), LV end-systolic diameter (LVESD), interventricular septum diameter at end-diastole (IVSDD), and end-diastolic posterior wall thickness (EDPWth) were assessed in long-axis parasternal 2D recordings, in left lateral decubitus position. Left ventricular end-diastolic volume (LVEDV) and LV end-systolic volume (LVESV) were calculated in apical 4- and 2-chamber view using the biplane method of disks (modified Simpson's method). The LVEF was estimated according to the following formula: (LVEDV - LVESV)/LVEDV $\times 100$ or by visual assessment in case of no possibility to accurately delineate (> 80\%) the LV endocardial border. The LV outflow tract (LVOT) and aortic annulus diameter were measured in parasternal long-axis and/or apical 3-chamber view (depending on the acoustic window quality), in zoom mode. The LVOT velocity and LVOT velocity time integral (VTI) were measured on spectral Doppler display using pulsed-wave Doppler. The continuous wave (CW) Doppler method was used to obtain 
the aortic valve peak velocities searching for an acoustic window with the highest values. Maximum and mean aortic valve pressure gradients were estimated by modified Bernoulli's equitation using the flow VTI over the ejection period in CW-Doppler recordings with a $50 \mathrm{~mm} / \mathrm{s}$ timescale on the $x$-axis. AVA was calculated according to the continuity equitation. Valvular regurgitations were assessed according to the current guidelines [33-35] semi-quantitatively and/or quantitatively, if possible. After TAVI, valvular regurgitations were defined according to Valve Academic Research Consortium (VARC) criteria [24]. Early and long-term TAVI effects were assessed using complete preprocedural TTE and complete TTE before discharge and during the follow-up period, respectively.

\section{Statistical analysis}

Continuous data are expressed as mean \pm standard deviation ( \pm SD), and categorical variables as numbers with percentages (\%). Baseline and follow-up data were compared by paired Student's $t$-test. The association between categorical variables was evaluated with the $\chi^{2}$ test. A value of $p<0.05$ was considered to be statistically significant. Statistical analysis was performed with IBM SPSS version 20 (SPSS Inc., Chicago, IL, USA).

\section{Results}

Initially, the study population composed of $170 \mathrm{pa}$ tients qualified to TAVI. Mean logistic EuroSCORE was $21.73 \pm 12.42 \%$ and the mean age was $79.9 \pm 7.5$ years. Clinical characteristics of the study population are presented in Table I.

Finally, TAVI was performed in 167 (98.2\%) patients. Two patients had only aortic balloon valvuloplasty due to technical problems during the procedure, and in 1 patient the procedure was cancelled because of life-threatening access site complications (eventually this female patient died). In the TAVI population, 3 types of prostheses were implanted: CV - in 87 (52.1\%) patients, ES/SXT in $78(46.7 \%)$ patients, and EV in $1(0.6 \%)$ patient. Seven (4.1\%) patients required second valve implantation due to a haemodynamically significant PL. Transfemoral access was the most frequent approach - in 128 (75.3\%) patients, including $87(51.2 \%)$ and 41 (24.1\%) patients with left and right femoral artery approach, respectively. Transapical approach was used in 24 (14.1\%) patients, anterior mini-thoracotomy in 7 (4.1\%) patients, subclavian artery approach in 9 (5.3\%) patients, and left axillary artery approach in 2 (1.2\%) patients. Device success was $78.8 \%$, and procedure success was $81.2 \%$. The 30 -day mortality rate was 13 (7.6\%), including 6 (3.5\%) patients who died shortly after the procedure (5 patients immediately after the procedure, 1 patient within $24 \mathrm{~h}$ ), and 7 (4.2\%) patients died within one month. In 2 patients, conversion do SAVR was needed. Because of these factors and technical issues, finally 161 echocardiographic
Table I. Clinical characteristics of the initial study population (170 patients qualified for TAVI)

\begin{tabular}{|c|c|c|}
\hline \multirow[t]{2}{*}{ Parameter } & \multicolumn{2}{|c|}{ Results } \\
\hline & $n$ & $\%$ \\
\hline Male & 54 & 31.8 \\
\hline Female & 116 & 68.2 \\
\hline \multicolumn{3}{|l|}{ NYHA functional class: } \\
\hline Class I & 0 & 0 \\
\hline Class II & 13 & 7.6 \\
\hline Class III & 138 & 81.2 \\
\hline Class IV & 19 & 11.2 \\
\hline Hypertension & 130 & 76.4 \\
\hline Diabetes mellitus type 2 & 58 & 34.1 \\
\hline Patients on insulin & 7 & 4.1 \\
\hline Coronary artery disease (CAD): & 123 & 72.3 \\
\hline Multivessel CAD & 89 & 52.3 \\
\hline Myocardial infarction & 35 & 20.5 \\
\hline Percutaneous coronary intervention (PCI) & 50 & 29.4 \\
\hline Coronary artery bypass grafting (CABG) & 25 & 14.7 \\
\hline Heart valve surgery & 7 & 4.1 \\
\hline Pacemaker prior to TAVI & 28 & 16.5 \\
\hline Chronic kidney disease (CKD): & 100 & 58.8 \\
\hline Requiring chronic dialysis & 2 & 1.2 \\
\hline Creatinine level, mean \pm SD $[\mu \mathrm{mol} / \mathrm{l}]$ & $103.11 \pm 41.46$ & - \\
\hline $\begin{array}{l}\text { Glomerular filtration rate (eGRF), } \\
\text { mean } \pm \mathrm{SD}\left[\mathrm{ml} / \mathrm{min} / 1.73 \mathrm{~m}^{2}\right]\end{array}$ & $55.68 \pm 18.22$ & - \\
\hline Anaemia: & 89 & 52.3 \\
\hline Haemoglobin level, mean \pm SD [g/dl] & $12.5 \pm 1.6$ & - \\
\hline $\begin{array}{l}\text { Chronic obstructive pulmonary disease } \\
\text { (COPD) }\end{array}$ & 32 & 18.8 \\
\hline Asthma & 3 & 1.8 \\
\hline Pulmonary hypertension & 25 & 14.7 \\
\hline Pulmonary embolism & 4 & 2.3 \\
\hline Emphysema & 6 & 3.5 \\
\hline Porcelain aorta & 13 & 7.6 \\
\hline Carotid artery stenosis ( $\geq 50 \%$ ) & 34 & 20 \\
\hline Stroke & 18 & 10.6 \\
\hline
\end{tabular}

examinations were analysed in TAVI patients prior to valve implantation and in 136 patients after the procedure - before discharge and during the follow-up period. Early and late post-procedural effects were assessed by echocardiography within a median of 6 and 185 days, respectively. The initial echocardiographic characteristics of patients are presented in Table II.

Statistically significant early decrease in maximal (96.0 $\pm 25.3 \mathrm{~mm} \mathrm{Hg}$ vs. $21.8 \pm 8.2 \mathrm{~mm} \mathrm{Hg}, p<0.001)$ and in mean aortic gradient $(58.6 \pm 16.7 \mathrm{~mm} \mathrm{Hg}$ vs. 11.9 $\pm 4.9 \mathrm{~mm} \mathrm{Hg}, p<0.001$ ) was observed (Figure 1). Also, early positive changes of LVEF were noted - there was a significant increase in LVEF in both short-term ( $57 \pm 14 \%$ vs. $59 \pm 13 \%, p<0.001)$ and long-term ( $56 \pm 14 \%$ vs. $60 \pm 12 \%$, $p<0.001$ ) observation (Figure 2). Significant decreases in IVSDD and EDPWth were observed also in early post TAVI $(15.0 \pm 2.4 \mathrm{~mm}$ vs. $14.5 \pm 2.3 \mathrm{~mm}, p<0.001$ and 12.7 $\pm 2.1 \mathrm{~mm}$ vs. $12.4 \pm 1.9 \mathrm{~mm}, p<0.028$, respectively) and 
Table II. Echocardiographic characteristics of the initial study population (170 patients)

\begin{tabular}{|c|c|c|}
\hline Parameter & \multicolumn{2}{|c|}{ Before TAVI } \\
\hline Maximal aortic gradient, mean \pm SD $[\mathrm{mm} \mathrm{Hg}]$ & \multicolumn{2}{|c|}{$96.0 \pm 25.3$} \\
\hline Mean aortic gradient, mean $\pm \mathrm{SD}[\mathrm{mm} \mathrm{Hg}]$ & \multicolumn{2}{|c|}{$58.6 \pm 16.7$} \\
\hline AVA (continuity equation $V T I)$, mean $\pm \mathrm{SD}\left[\mathrm{cm}^{2}\right]$ & \multicolumn{2}{|c|}{$0.66 \pm 0.15$} \\
\hline IVSDD, mean \pm SD $[\mathrm{mm}]$ & \multicolumn{2}{|c|}{$15.0 \pm 2.4$} \\
\hline EDPWDth, mean \pm SD $[\mathrm{mm}]$ & \multicolumn{2}{|c|}{$12.7 \pm 2.1$} \\
\hline LVEDD, mean \pm SD [mm] & \multicolumn{2}{|c|}{$47.4 \pm 7.5$} \\
\hline LVESD, mean \pm SD $[\mathrm{mm}]$ & \multicolumn{2}{|c|}{$31.3 \pm 9.0$} \\
\hline LVEF, mean \pm SD $(\%)$ & \multicolumn{2}{|c|}{$57 \pm 14$} \\
\hline & $n$ & $\%$ \\
\hline $\begin{array}{l}\text { LVEF (\%): } \\
>50 \\
40-49 \\
30-39 \\
<30\end{array}$ & $\begin{array}{c}129 \\
11 \\
24 \\
6\end{array}$ & $\begin{array}{c}75.9 \\
6.5 \\
14.1 \\
3.5\end{array}$ \\
\hline msMR & 24 & 14.9 \\
\hline
\end{tabular}

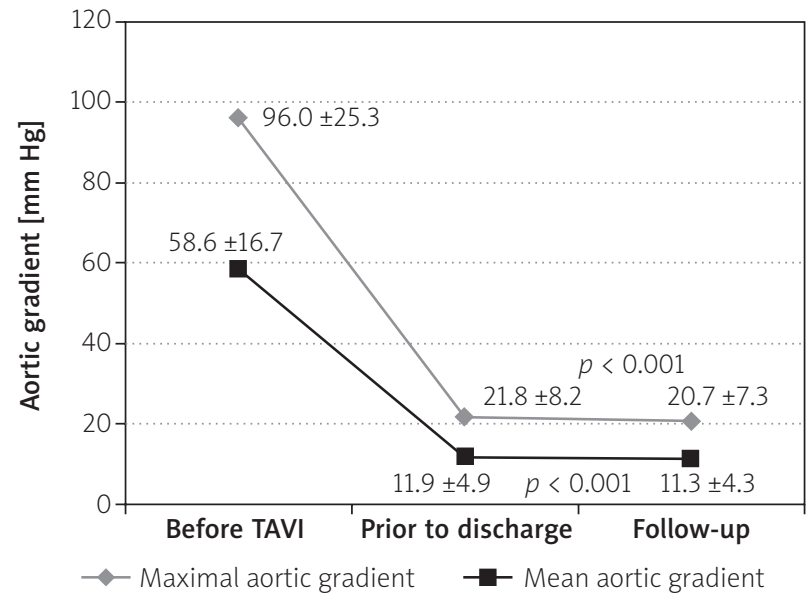

Figure 1. Reduction in maximal and mean transvalvular aortic gradient after TAVI

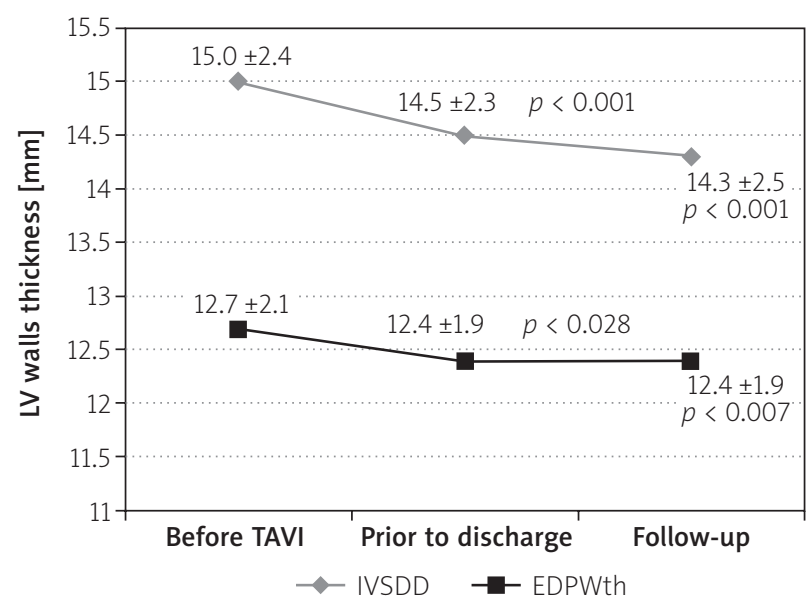

Figure 3. Reduction in LV wall thickness after TAVI late post TAVI $(15.1 \pm 2.5 \mathrm{~mm}$ vs. $14.3 \pm 2.5 \mathrm{~mm}, p<0.001$ and $12.8 \pm 2.0 \mathrm{~mm}$ vs. $12.4 \pm 1.9 \mathrm{~mm}, p<0.007$, respectively) period (Figure 3). The LVEDD decrease after TAVI in the first observations was non-significant $(47.4 \pm 7.5 \mathrm{~mm}$ vs. $47.6 \pm 7.0 \mathrm{~mm}, p<0.541)$ but was statistically significant during follow-up (47.3 $\pm 7.6 \mathrm{~mm}$ vs. $46.1 \pm 7.5 \mathrm{~mm}$, $p<0.030)$. In case of LVESD, the decrease was not significant either in short-term $(31.3 \pm 9.0 \mathrm{~mm}$ vs. $30.0 \pm 8.4 \mathrm{~mm}$, $p<0.062)$ or in long-term (30.9 \pm 8.4 vs. $30.1 \pm 7.9$, $p<0.261)$ echocardiograms. Moderate/severe PL was observed in $21(13.1 \%)$ patients before hospital discharge but in 13 (9.6\%) patients during follow-up $(p<0.001$, Figure 4). Significant MR was seen in 24 (14.9\%) patients of the initial group but in $19(11.8 \%)$ patients in an early and in late period after TAVI $(p<0.001$, Figure 4).

\section{Discussion}

Similarly to studies and registries evaluating TAVI effects [9], we observed a comparably statistically signifi-

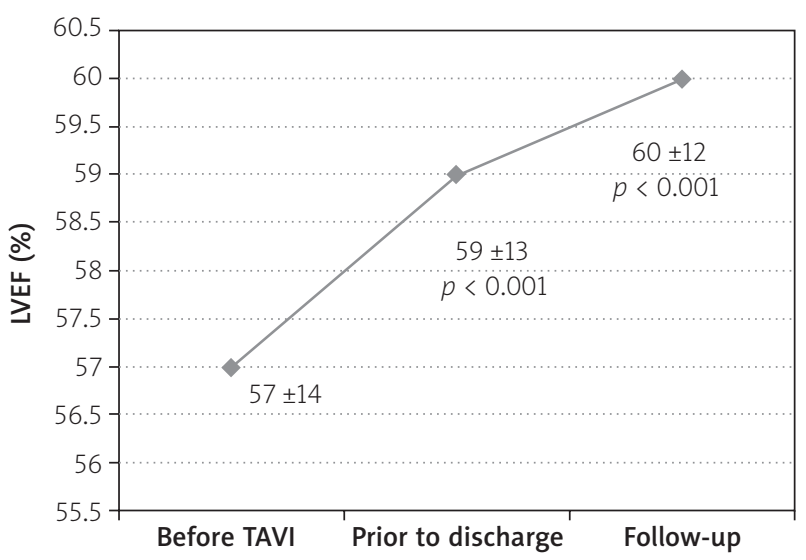

Figure 2. LVEF increase after TAVI

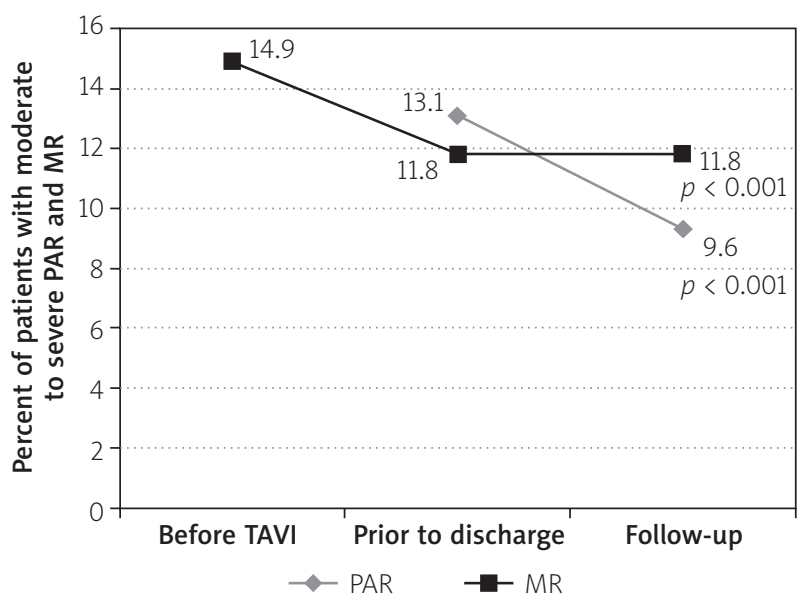

Figure 4. Paravalvular aortic regurgitation (PAR) and mitral regurgitation (MR) after TAVI 
cant early decrease in mean aortic gradient, which was the main aim of the procedure - afterload reduction subsequently translates into the improvement of LV parameters and better clinical condition and survival. Cribier et al. observed a rapid and significant decrease in transvalvular gradients after TAVI in the early post-procedural period [36-38]. If the TAVI procedure was not performed for technical reasons and then a significant reduction in meant aortic gradient could not be achieved, heart failure symptoms were definitely more pronounced and the mortality rate was significantly higher.

Rapid and significant increase in LVEF - within $24 \mathrm{~h}$ after TAVI - was also demonstrated in first Cribier's observations [37]. Similarly to our study, the significant improvement in LVEF before hospital discharge in patients subjected to TAVI was also noted in recent observations [10-12, 16, 39]. However, De Jaegere et al. [40] and Tzikas et al. [17] did not notice the comparably fast LVEF improvement (in $6 \pm 2$ and $80 \pm 64$ days or 365 days, respectively), which may have resulted from the small patient groups. A fast increase in LVEF translates into almost immediate heart failure symptoms alleviation and clinical improvement and is thus correlated with better late survival. It seems that the lower the baseline LVEF, the better the LVEF improvement [11, 12], which was noted in the very first observations after TAVI procedures. According to more recent observations by Unbehaun et al., considering patients with very low LVEF and/or with cardiogenic shock, the early LVEF increase was significantly higher when it was $\leq 20 \%$ prior to the procedure [39]. Moreover, some studies indicate that the improvement of LV performance in patients with basic LV systolic dysfunction due to AS is better after TAVI than after SAVR [41]. Further statistically significant improvement of LVEF seen in our group in follow-up echocardiograms shows the long-term efficacy of TAVI.

Publications concerning the pace of LV wall thickness reduction after TAVI differ. Jilaihawi et al. were the first to observe an early (just 1 month after TAVI), significant (13\%) reduction in IVSDD comparable to that observed 1 year after SAVR [42]. More recent observations by Vizzardi et al. [43] in a group of 135 patients also show a significant (again 13\%) reduction in IVSDD as well as in EDPWth (16\%), but 6 months after TAVI, comparable to the SAVR effects in the systematic review of 27 studies concerning 1546 patients, in which significant regression of LVH was observed up to 6 months after open heart surgery [44]. Conversely, Tzikas et al. [17] reported a significant regression of $\mathrm{LVH}$ in TAVI patients only after 1 year of observation. In our study, like Jilaihawi et al., we demonstrated an early decrease in IVSDD, but also in EDPWth. We showed IVSDD and EDPWth decrease in long-term follow-up as well. Indeed, the latest analysis of a patient population included in the PARTNER trial seems to confirm that these observations show a significant regression of LVH within 30 days of TAVI and in the one-year follow-up period [20]. Importantly, patients with the biggest early $\mathrm{LVH}$ regression were less than half as likely to require re-hospitalisation during the year after TAVI. It seems that early LVH regression due to afterload reduction is associated with the regression of contractile elements of cardiomyocyte, and its late reduction results from time-consuming interstitial collagen matrix remodelling [45]. Regression of LV wall thickness after TAVI or SAVR is associated with reverse remodelling and improvement of systolic and diastolic function, as well as with better survival $[16,46,47]$.

We observed significant (moderate or severe) PL after TAVI in $13.1 \%$ and in $9.6 \%$ of our patients in short- and in long-term follow-up, respectively. No significant transvalvular leak was recorded, which is confirmed by prior observations. According to a number of TAVI registries, significant transvalvular leakages occur rarely. However, $\mathrm{PL}$ is observed quite frequently [13]. It is estimated that significant PL occurs in $7 \%$ to $24 \%$ of patients, and the results of follow-up examinations confirm that the degree of leak tends to decrease, rather than increase [13]. It was shown that significant PL adversely affects LV performance and patient survival [14].

Significant moderate or severe mitral regurgitation (msMR) is frequent in patients undergoing TAVI [48]. In our study, msMR in the initial group was observed in $24(14.9 \%)$ patients and in $19(11.8 \%)$ patients in both short- and long-term follow-up ( $p<0.001)$. According to Khawaja et al. [48], msMR occurred initially in not less than $19 \%$ of patients and in less than $8 \%$ of patients after the procedure, during a 30-day observation period. They showed that one-year and all-cause mortality was higher if there was msMR observed before TAVI. Indeed, reduced grade of concomitant MR was associated with decreased mortality rate. Similarly, according to Sannino et al. [15] in their meta-analysis of 13 studies concerning 4839 patients who underwent TAVI, the mortality rate of patients with msMR was already significantly higher in a 30-day period but also in 1-year and 2-year follow-up, regardless of LVEF value. Significant MR definitely had negative impact on TAVI results, and a trend toward a reduction in msMR was noted.

In our study, we did not find any early, statistically significant decrease in LV dimensions, which is comparable to a few earlier reports $[16,17]$. However, a significant reduction in LVDD was noted in long-term follow-up.

\section{Conclusions}

Our study, concerning the biggest population of patients with severe AS subjected to TAVI in one centre in Poland, demonstrates that the procedure, in a short period of time (within a median of 6 days), can improve LV performance and parameters. A rapid increase in LVEF and fast decrease in LV wall thickness as well as a rapid, advantageous reduction of significant $M R$ can be 
achieved. However, there was no early decrease in LV dimensions. The incidence of significant PL was similar to previous studies and registries and tended to decrease with time.

\section{Acknowledgments}

The authors wish to thank Joanna Duliban, Katarzyna Faber, Jarosław Kusz, and Tomasz Pokładnik for their help in echocardiographic database preparation.

\section{Conflict of interest}

The authors declare no conflict of interest.

\section{References}

1. Osnabrugge RLJ, Mylotte D, Head SJ, et al. Aortic stenosis in the elderly: disease prevalence and number of candidates for transcatheter aortic valve replacement: a meta-analysis and modeling study. J Am Coll Cardiol 2013; 62: 1002-12.

2. Vahanian A, Alfieri O, Andreotti F, et al. Guidelines on the management of valvular heart disease (version 2012): the Joint Task Force on the Management of Valvular Heart Disease of the European Society of Cardiology (ESC) and the European Association for Cardio-Thoracic Surgery (EACTS). Eur J Cardiothorac Surg 2012; 42: S1-44.

3. Brown JM, O'Brien SM, Wu C, et al. Isolated aortic valve replacement in North America comprising 108,687 patients in 10 years: changes in risks, valve types, and outcomes in the Society of Thoracic Surgeons National Database. J Thorac Cardiovasc Surg 2009; 137: 82-90.

4. Chukwuemeka A, Borger MA, Ivanov J, et al. Valve surgery in octogenarians: a safe option with good medium-term results. J Heart Valve Dis 2006; 15: 191-6.

5. lung B, Baron G, Butchart EG, et al. A prospective survey of patients with valvular heart disease in Europe: The Euro Heart Survey on Valvular Heart Disease. Eur Heart J 2003; 24: 1231-43.

6. lung B, Cachier A, Baron G, et al. Decision-making in elderly patients with severe aortic stenosis: why are so many denied surgery? Eur Heart J 2005; 26: 2714-20.

7. Cribier A, Eltchaninoff $\mathrm{H}$, Bash A, et al. Percutaneous transcatheter implantation of an aortic valve prosthesis for calcific aortic stenosis: first human case description. Circulation 2002; 106: 3006-8.

8. Adams DH, Popma JJ, Reardon MJ, et al. Transcatheter aortic-valve replacement with a self-expanding prosthesis. N Engl J Med 2014; 370: 1790-8.

9. Généreux P, Head SJ, Wood DA, et al. Transcatheter aortic valve implantation 10-year anniversary: review of current evidence and clinical implications. Eur Heart J 2012; 33: 2388-98.

10. Ayhan H, Kasapkara HA, Durmaz T, et al. Impact of transcatheter aortic valve implantation in patients with reduced ejection fraction. Cardiol J 2014. doi: 10.5603/CJ.a2014.0040.

11. Fraccaro C, Al-Lamee R, Tarantini G, et al. Transcatheter aortic valve implantation in patients with severe left ventricular dysfunction: immediate and mid-term results, a multicenter study. Circ Cardiovasc Interv 2012; 5: 253-60.

12. Pilgrim T, Wenaweser P, Meuli F, et al. Clinical outcome of highrisk patients with severe aortic stenosis and reduced left ventricular ejection fraction undergoing medical treatment or TAVI. PLoS One 2011; 6: e27556.
13. Généreux P, Head SJ, Wood DA, et al. Transcatheter aortic valve implantation: 10-year anniversary Part II: clinical implications. Eur Heart J 2012; 33: 2399-402.

14. Schewel D, Frerker C, Schewel J, et al. Clinical impact of paravalvular leaks on biomarkers and survival after transcatheter aortic valve implantation. Catheter Cardiovasc Interv 2013 doi: 10.1002/ccd.25295.

15. Sannino A, Losi MA, Schiattarella GG, et al. Meta-analysis of mortality outcomes and mitral regurgitation evolution in 4,839 patients having transcatheter aortic valve implantation for severe aortic stenosis. Am J Cardiol 2014; 114: 875-82.

16. Giannini C, Petronio AS, Nardi C, et al. Left ventricular reverse remodeling in percutaneous and surgical aortic bioprostheses: an echocardiographic study. Am Soc Echocardiogr 2011; 24: 28-36.

17. Tzikas A, Geleijnse ML, Van Mieghem NM, et al. Left ventricular mass regression one year after transcatheter aortic valve implantation. Ann Thorac Surg 2011; 91: 685-91.

18. Ewe SH, Delgado V, Ng AC, et al. Outcomes after transcatheter aortic valve implantation: transfemoral versus transapical approach. Ann Thorac Surg 2011; 92: 1244-51.

19. Stangl V, Baldenhofer G, Knebel F, et al. Impact of gender on three-month outcome and left ventricular remodeling after transfemoral transcatheter aortic valve implantation. Am J Cardiol 2012; 110: 884-90.

20. Lindman BR, Stewart WJ, Pibarot P, et al. Early regression of severe left ventricular hypertrophy after transcatheter aortic valve replacement is associated with decreased hospitalizations. JACC Cardiovasc Interv 2014; 7: 662-73.

21. Nashef SA, Roques F, Michel P, et al. European System for Cardiac Operative Risk Evaluation (EuroSCORE). Eur J Cardiothorac Surg 1999; 16: 9-13.

22. Durand E, Borz B, Godin M, et al. Performance analysis of EuroSCORE II compared to the original logistic EuroSCORE and STS scores for predicting 30-day mortality after transcatheter aortic valve replacement. Am J Cardiol 2013; 111: 891-7.

23. Fried LP, Tangen CM, Walston J, et al. Frailty in older adults. J Gerontol A Biol Sci Med Sci 2001; 56: 146-56.

24. Kappetein AP, Head SJ, Généreux P, et al. Updated standardized endpoint definitions for transcatheter aortic valve implantation: the Valve Academic Research Consortium-2 consensus document. Eur Heart J 2012; 33: 2403-18.

25. Leon MB, Piazza N, Nikolsky E, et al. Standardized endpoint definitions for transcatheter aortic valve implantation clinical trials: a consensus report from the Valve Academic Research Consortium. J Am Coll Cardiol 2011; 57: 253-69.

26. Leon MB, Piazza N, Nikolsky E, et al. Standardized endpoint definitions for transcatheter aortic valve implantation clinical trials: a consensus report from the Valve Academic Research Consortium. Eur Heart J 2011; 32: 205-17.

27. Covello RD, Maj G, Landoni G, et al. Anesthetic management of percutaneous aortic valve implantation: focus on challenges encountered and proposed solutions. J Cardiothorac Vasc Anesth 2009; 23: 280-5.

28. Kasprzak JD, Hoffman P, Płońska E, et al. Echokardiografia w praktyce klinicznej - Standardy Sekcji Echokardiografii Polskiego Towarzystwa Kardiologicznego 2007 [Polish]. Kardiol Pol 2007; 65: 8.

29. Evangelista A, Flachskampf F, Lancellotti P, et al. European Association of Echocardiography Recommendations for standardization of performance, digital storage and reporting of echocardiographic studies. Eur J Echocardiogr 2008; 9: 438-48. 
30. Hahn RT, Abraham T, Adams MS, et al. Guidelines for performing a comprehensive transesophageal echocardiographic examination: recommendations from the American Society of Echocardiography and the Society of Cardiovascular Anesthesiologists. J Am Soc Echocardiogr 2013; 26: 921-64.

31. Flachskampf FA, Badano L, Daniel WG, et al. Recommendations for transoesophageal echocardiography: update 2010. Eur J Echocardiogr 2010; 11: 557-76.

32. Flachskampf FA, Decoodt P, Fraser AG, et al. Subgroup on transesophageal echocardiography and valvular heart disease; Working Group on Echocardiography of the European Society of Cardiology. Guidelines from the Working Group. Recommendations for performing transesophageal echocardiography. Eur J Echocardiogr 2001; 2: 8-21.

33. Lancellotti P, Tribouilloy C, Hagendorff A, et al. European Association of Echocardiography recommendations for the assessment of valvular regurgitation. Part 1: aortic and pulmonary regurgitation (native valve disease), Eur J Echocardiogr 2010; 11: 223-44.

34. Lancellotti P, Moura L, Pierard LA, et al. European Association of Echocardiography recommendations for the assessment of valvular regurgitation. Part 2: mitral and tricuspid regurgitation (native valve disease). Eur J Echocardiogr 2010; 11: 307-32.

35. Zoghbi WA, Enriquez-Sarano M, Foster E, et al. Recommendations for evaluation of the severity of native valvular regurgitation with two-dimensional and Doppler echocardiography. J Am Soc Echocardiogr 2003; 16: 777-802.

36. Cribier A, Eltchaninoff H, Tron C, et al. Early experience with percutaneous transcatheter implantation of heart valve prosthesis for the treatment of end-stage inoperable patients with calcific aortic stenosis. J Am Coll Cardiol 2004; 43: 698-703.

37. Bauer F, Eltchaninoff H, Tron C, et al. Acute improvement in global and regional left ventricular systolic function after percutaneous heart valve implantation in patients with symptomatic aortic stenosis. Circulation 2004; 110: 1473-6.

38. Cribier A, Eltchaninoff $H$, Tron C, et al. Treatment of calcific aortic stenosis with the percutaneous heart valve: mid-term follow-up from the initial feasibility studies: the French experience. J Am Coll Cardiol 2006; 47: 1214-23.

39. Unbehaun A, Pasic M, Buz S, et al. Aortic valve implantation in patients with poor left ventricular function and cardiogenic shock. J Thorac Cardiovasc Surg 2014; 148: 2877-82.e1.

40. De Jaegere PP, Piazza N, Galema TW, et al. Early echocardiographic evaluation following percutaneous implantation with the self-expanding CoreValve ReValving system aortic valve bioprosthesis. Eurolntervention 2008; 4: 351-7.

41. Clavel MA, Webb JG, Rodes-Cabau J, et al. Comparison between transcatheter and surgical prosthetic valve implantation in patients with severe aortic stenosis and reduced left ventricular ejection fraction. Circulation 2010; 122: 1928-36.

42. Jilaihawi $H$, Jeilan $M$, Spyt $T$, et al. Early regression of left ventricular wall thickness following percutaneous aortic valve replacement with the CoreValve bioprosthesis. I Invasive Cardiol 2009; 21: 151-5.

43. Vizzardi E, D’Aloia A, Fiorina C, et al. Early regression of left ventricular mass associated with diastolic improvement after transcatheter aortic valve implantation. J Am Soc Echocardiogr 2012; 25: 1091-8

44. Sharma UC, Barenbrug P, Pokharel S, et al. Systematic review of the outcome of aortic valve replacement in patients with aortic stenosis. Ann Thorac Surg 2004; 78: 90-5.
45. Villari B, Vassalli G, Betocchi S, et al. Normalization of left ventricular nonuniformity late after valve replacement for aortic stenosis. Am J Cardiol 1996; 78: 66-71.

46. Ewe SH, Ajmone Marsan N, Pepi M, et al. Impact of left ventricular systolic function on clinical and echocardiographic outcomes following transcatheter aortic valve implantation for severe aortic stenosis. Am Heart J 2010; 160: 1113-20.

47. D’Ascenzi F, Cameli M, Iadanza A, et al. Improvement of left ventricular longitudinal systolic function after transcatheter aortic valve implantation: a speckle-tracking prospective study. Int J Cardiovasc Imaging 2013; 29: 1007-15.

48. Khawaja MZ, Williams R, Hung J, et al. Impact of preprocedural mitral regurgitation upon mortality after transcatheter aortic valve implantation (TAVI) for severe aortic stenosis. Heart 2014; 100: 1799-803. 